\title{
FUZZY MODELING OF THE EFFECTS OF IRRIGATION AND WATER SALINITY IN HARVEST POINT OF TOMATO CROP. PART I: DESCRIPTION OF THE METHOD
}

\author{
Daniel dos S. Viais Neto ${ }^{1}$, Camila P. Cremasco², Deyver Bordin ${ }^{3}$, Fernando F. Putti², \\ Josué F. Silva Junior ${ }^{4}$, Luís R. A. Gabriel Filho ${ }^{*}$
}

\author{
${ }^{5 *}$ Corresponding author. São Paulo State University (UNESP), School of Sciences and Engineering/ Tupã - SP, Brasil. \\ E-mail: gabriel.filho@unesp.br | ORCID ID: http://orcid.org/0000-0002-7269-2806
}

\section{KEYWORDS}

fuzzy logic, drought, salt stress, crop management.

\begin{abstract}
It was used statistical techniques for the evaluation of agricultural experiments, but there are mathematical theories that allow finer adjustments, highlighting among them, the fuzzy logic. The objective of the study was characterizing a method of fuzzy modeling from an agronomic experiment. For this study it was used data from an experiment conducted at the School of Agriculture of São Paulo State University (UNESP) in Botucatu-SP. The system input variables based in fuzzy rules were soil water tension and doses of water salinity, being defined three fuzzy sets. The output variables was elected from the biometric and productivity analysis that showed statistically significant differences, namely, plant height, stem diameter, leaf area, green biomass, dry weight, number of fruits, average fruit weight and percentage of disabled fruits. For output variables 9 fuzzy sets were defined. From the adopted methodology, the model allowed extract directly from the data set a base of rules without the use of questionnaires to experts for its preparation. In addition, it will analyze intermediate regions at trial levels and weave other conclusions of the tomato growth and productivity, not limiting in this way only those observed with statistical analysis.
\end{abstract}

\section{INTRODUCTION}

Imported from the Andean region to Europe in the 16th century, today tomato is widespread throughout the world (Bergougnoux, 2014) and additionally, it has easy adaptation to a wide variety of climates, except those where frosts are present (Rosa et al., 2011). "The table tomato or for consumption in natura is produced in almost all Brazil regions and at different times under different cropping systems and different levels of management" (Matos et al., 2012) also stands out "as the second most widely grown vegetable in the world exceeded only by potato" (Santos et al., 2011).

Santana et al. (2009) state that the tomato crop is demanding in cultural practices such as irrigation and that the water deficit is responsible for affecting the tomato production, and according to Filgueira (2013), also influences the quality of the fruit and even reduces the incidence of physiological abnormalities, especially the apical rot.
Regarding the water used for tomato irrigation, Alvarenga (2004) infers that should be of good quality, free of biological contaminants in addition, the salt content should be less than $1.5 \mathrm{~g} \mathrm{~L}^{-1}$ (equivalent to electrical conductivity less than $2.2 \mathrm{dS} \mathrm{m}^{-1}$ ). "In extreme salinity situations, the tomato crop is not able to perform the osmotic adjustment required to meet its water demand, and therefore for nutrient, causing decrease in turgor and productivity" (Silva Junior, 2012). In general, the salts of irrigation water reduces significantly, plant height, leaf area, production of shoot dry matter and fruit production of tomato crop (Oliveira et al., 2007).

In agricultural experimentation, which aims to investigate causes and effects of new technologies, resource optimization, reuse of solid and liquid waste among others, use statistical techniques to infer the best results, but to express the intermediate values, which are not tested experimentally, regression models are usually employed (Putti, 2015).

\footnotetext{
${ }^{1}$ São Paulo State Faculty of Technology (FATEC)/ Presidente Prudente - SP, Brasil.

${ }^{2}$ São Paulo State University (UNESP), School of Sciences and Engineering/ Tupã - SP, Brasil.

${ }^{3}$ São Paulo State University (UNESP), School of Agriculture/ Botucatu - SP, Brasil.

${ }^{4}$ Federal University of the Triângulo Mineiro/ Iturama - MG, Brasil.

Received in: 7-11-2018
}

Accepted in: 3-26-2019 
One way of modeling that is gaining prominence is the one that uses of fuzzy logic, introduced in scientific circles by Zadeh (1965), which makes use of mathematical and computational theories with more refined adjustments in relation to regression. This type of modeling brings the ease of understanding phenomena in many areas becoming an important theory in the analysis of results.

Examples of applications of different uses of this theory in agricultural engineering are characterized in models on cattle body mass (Gabriel Filho et al., 2011, 2016), dynamic quality of agricultural soils in relation to their biological, physical and chemistry characteristics (Rodríguez et al., 2016.), development of irrigated lettuce with different types of water (Putti, 2015), commercialization of cassava (Gabriel Filho et al., 2015), estimate the effects of global warming on the vitality of Laelia purpurata orchids (Putti et al., 2017), crop classification (Murmu \& Biswas 2015), land use planning of agricultural production systems (Mishra et al., 2014), agro-meteorological models for yield estimation (Luydmila et al., 2017) and agricultural optimal cropping pattern determination (Neamatollahi et al., 2017)

Several models are developed using area experts for the development of rules base, system core based on fuzzy rules. However, many conducted agronomic experiments can, from their measured data, provide such information that field experts would do it, and with a degree of accuracy according to the data. With this, it creates a reverse phenomenon: the data themselves provide rules that expert would provide. This is one of the proposals in this methodology applied in the behavior of the tomato biometric variables front of different water tensions in soil and doses of water salinity.

Thus, the aim of this study was to characterize a method of fuzzy modeling from an agronomic experiment to evaluate the effects on the growth and productivity of hybrid tomato (Licopersicum esculentum) at different water tensions in soil and different salinity irrigation doses to 120 days after sowing.

\section{MATERIAL AND METHODS}

\section{Experiment description}

The experimental data used for fuzzy modeling of this study were statistically analyzed in Silva Junior (2012). The experiment was carried out between June and October of 2011, in a protected environment installed in an area with an average altitude of $786 \mathrm{~m}$, latitude $22^{\circ} 5^{\prime} 03^{\prime \prime}$ South, longitude equal to $48^{\circ} 25^{\prime} 37^{\prime}$ "West and situated in the Department of Rural Engineering of the School of Agriculture of São Paulo State University (UNESP) in Botucatu SP.

The irrigation management was established to supply water to the crop in three conditions of potential soil water matrix ( $\Psi=-60,-30$ and $-10 \mathrm{kPa})$. Furthermore, the water used for irrigation had electrical conductivity (EC) of 0.08 (no salt added) and the concentrations of 3 and $5 \mathrm{dS}$ $\mathrm{m}^{-1}$. Thus, we used three doses of salinity in the experiment. Therefore, the experimental design was completely randomized, double factorial design with three replications, three water tensions on the ground and three levels of salinity.

The tomato biometric parameters and productivity measured by Silva Junior (2012) at 120 days after sowing were: plant height $(\mathrm{PH}, \mathrm{cm})$, stem diameter $(\mathrm{SD}, \mathrm{cm})$, leaf area $\left(\mathrm{LA}, \mathrm{cm}^{2}\right)$, green biomass $(\mathrm{GB}, \mathrm{g})$, dry biomass (DB, $\mathrm{g}$ ), fruit number (FN, units), average fruit weight (AFW, g) and percentage of disabled fruits (PDF, \%).

\section{Fuzzy modeling}

From the experiment conducted by Silva Junior (2012), which was used the management of different water tensions in soil (irrigation) and different irrigation salinity doses (salinity) along the tomato cycle, it was held a fuzzy modeling to study the effects on the biometric variables and productivity in the harvest point of this crop that occurred 120 days after sowing (DAS).

Therefore, it was considered the following model to represent the agronomic experiment in study: $F: X_{1} \times X_{2} \subseteq$ $\mathbb{R}^{2} \rightarrow \mathbb{R}^{8}, \quad\left(x_{1}, x_{2}\right) \mapsto Y=F\left(x_{1}, x_{2}\right), \quad$ where $X_{1}=[-60,-10], X_{2}=[0,08 ; 5], \mathbb{R}$ is the set of real numbers, $x_{1}$ represents the soil water tension $(\mathrm{kPa})$ and $x_{2}$ the salinity dose in irrigation $\left(\mathrm{dS} \mathrm{m}^{-1)}\right.$. Extremes of the ranges $X_{1}$ and $X_{2}$ are in accordance with the minimum and maximum values used in the experiment. Additionally, $Y=F\left(x_{1}, x_{2}\right)=\left(y_{1}, y_{2}, \ldots, y_{8}\right)$ defined by the tomato median biometric and productivity variables and $y_{1}=\mathrm{PH}$, $y_{2}=\mathrm{S} D, y_{3}=L A, y_{4}=G B, y_{5}=D B, y_{6}=\mathrm{F} N, \quad y_{7}=$ $A F W$ and $y_{8}=P D F$.

For the development of the Fuzzy Rule-Based Systems (FRBS), was defined an input processor (or fuzzyficator), a set of linguistic rules, a method of fuzzy inference and an output processor (or de-fuzzyficator) generating as output a real number (Figure 1). 


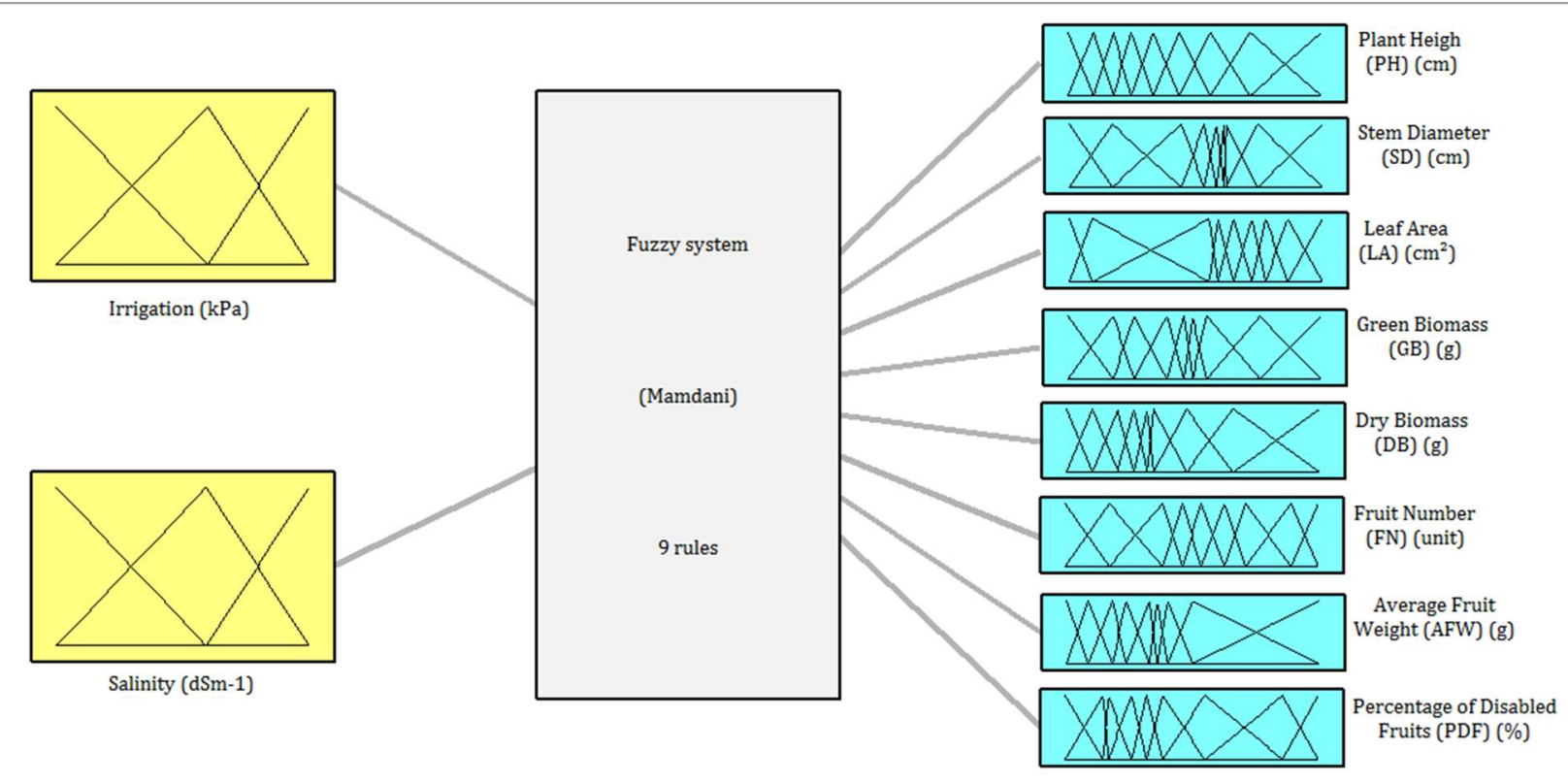

FIGURE 1. Tomato Fuzzy Rule-Based Systems (FRBS) evaluation with 2 input variables (Irrigation and Salinity), 8 output variables (plant height, stem diameter, leaf area, green biomass, dry biomass, fruit number, average fruit weight and percentage of disabled fruits) and 9 rules.

This FRBS represents a function $F: X_{1} \times X_{2} \subseteq$ $\mathbb{R}^{2} \rightarrow \mathbb{R}^{8}$ such that $F=\left(f_{1}\left(x_{1}, x_{2}\right), f_{2}\left(x_{1}, x_{2}\right), f_{3}\left(x_{1}, x_{2}\right)\right.$, $\left.f_{4}\left(x_{1}, x_{2}\right), f_{5}\left(x_{1}, x_{2}\right), f_{6}\left(x_{1}, x_{2}\right), f_{7}\left(x_{1}, x_{2}\right), f_{8}\left(x_{1}, x_{2}\right)\right)$, where the Cartesian product which is the domain represents the soil water tensions $\left(X_{1}=[-60,-10]\right)$ and the salinity irrigation doses $\left.X_{2}=[0,08 ; 5]\right)$. The codomain $\mathbb{R}^{8}$ represents the eight output variables evaluated: $\mathrm{PH}, \mathrm{SD}, \mathrm{LA}$, $\mathrm{GB}, \mathrm{DB}, \mathrm{FN}, \mathrm{AFW}$ and PDF, in this order.

\section{Fuzzy sets of the input variables}

The FRBS input variables developed were irrigation and salinity. For both variables were defined three fuzzy sets called Low (L), Medium (M) and High (H) according to Table 1, whose numerical values were taken from the analysis of the experiment data held in Silva Junior (2012).

The pertinence functions were prepared so that the soil water tensions adopted in the experiment $(-60,-30$ and $-10 \mathrm{kPa})$ presented degree of pertinence equal to 1 in the fuzzy sets $\mathrm{L}, \mathrm{M}$ and $\mathrm{H}$ respectively. The same procedure was used for the salinity doses in the irrigation adopted in the experiment $\left(0.08 ; 3\right.$ and $\left.5 \mathrm{dS} \mathrm{m}^{-1}\right)$.

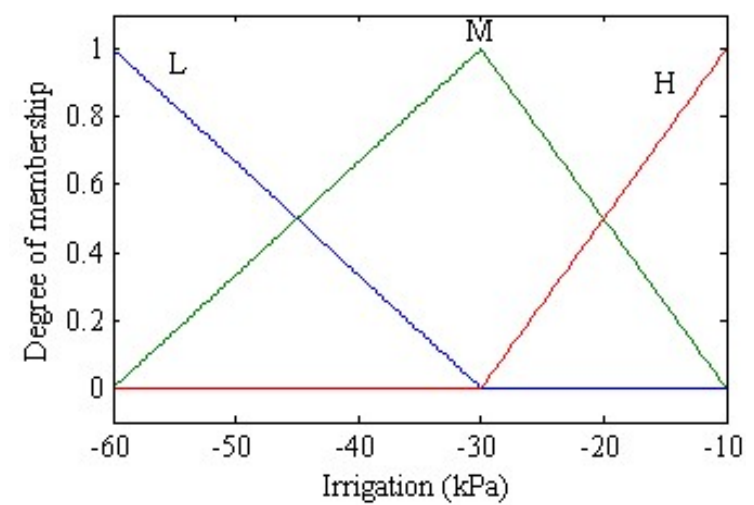

(a)
TABLE 1. Definition of the triangular membership functions of fuzzy sets Low (L), Medium (M) and High (H) for the input variables Irrigation and Salinity.

\begin{tabular}{cccc}
\hline Fuzzy Sets & Type & $\begin{array}{c}\text { Irrigation } \\
\text { delimiters }\end{array}$ & $\begin{array}{c}\text { Salinity } \\
\text { delimiters }\end{array}$ \\
\hline L & Triangular & {$[-61,-60,-30]$} & {$[-0.92,0.08,3]$} \\
M & Triangular & {$[-60,-30,-10]$} & {$[0.08,3,5]$} \\
H & Triangular & {$[-30,-10,-9]$} & {$[3,5,6]$} \\
\hline
\end{tabular}

Thus, it was adopted for the "L" set in its first delimiter the point $P_{1}-1$, so that the degree of pertinence 1 occurs either for the soil water tension at $-60 \mathrm{kPa}$ as for the soil salinity irrigation dose of $0.08 \mathrm{dS} \mathrm{m}^{-1}$, since it is experimentally observed points. Similarly, it was adopted for " $H$ " set in its last delimiter the $P_{3}+1$ point. Thus, both the soil water tension of $-10 \mathrm{kPa}$ as the salinity irrigation dose of $5 \mathrm{dS} \mathrm{m}^{-1}$ obtained degree of pertinence 1 . This procedure was used by Cremasco et al. (2010), Gabriel Filho et al. (2011), Pereira et al. (2008), Putti et al. (2014, 2017), Putti (2015) and Gabriel Filho et al. (2016).

The pertinence functions of the irrigation and salinity variables are shown in Figure 2.

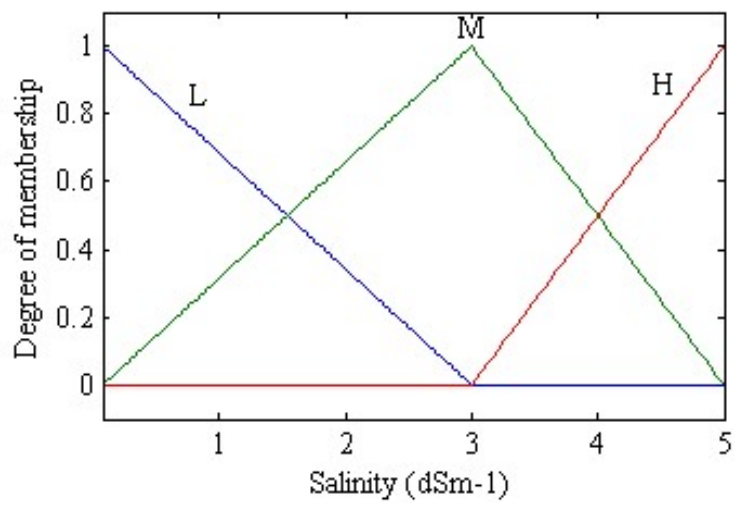

(b)

FIGURE 2. Triangular membership functions of fuzzy sets low, medium and high for the input variables (a) Irrigation and (b) Salinity. 


\section{Fuzzy sets of output variables}

It was elected all the above output variables as they presented significant differences between the soil water tensions and / or salinity irrigation doses 120 days after sowing and / or interactions between these factors, according to Silva Junior (2012), with level of significance $\alpha=5 \%$.

Generalizing the methodology of the FRBS output variables 9 fuzzy sets were defined called Low 1 (L1), Low 2 (L2), Low 3 (L3), Medium 1 (M1), Medium 2 (M2), Medium 3 (M3), High 1 (H1), High 2 (H2) and High 3 (H3), seeking with such a large number of fuzzy sets increase the accuracy of the model. In order to reduce complexity, the triangular fuzzy sets were adopted as they are commonly used and need only determine the peak value and the width of its base. Therefore, it was necessary to create delimiters that enabled to define in a triangular shape each of the pertinence functions of each of these fuzzy sets in question.
The following calculations for determining such delimiters are similar to the methodological procedures adopted in Putti (2015) and Gabriel Filho et al. (2016).

In this case, the triangular pertinence functions require the calculation of 9 delimiters, which were defined as percentiles of the data set being measured in each output variable. These percentiles $x \%$, denoted by $P(x \%)$, depend on a constant $k$, once the 9 necessary delimiters are of the form $P(m k), 0 \leq m \leq 8$. The constant $k$ was calculated as follows:

$$
8 k=100 \% \Rightarrow k=\frac{100 \%}{8} \Rightarrow k=12.5 \% \text {. }
$$

Table 2 and Figure 3 show the definition of pertinence functions for the output variables using percentiles varying in $12.5 \%$. It is noteworthy that for the pertinence functions $\mathrm{L} 1$ and $\mathrm{H} 3$, one of two disjoint intervals holder whose points have not degree of pertinence 1 was defined with amplitude equal to 1 .

TABLE 2. Definition of the percentiles delimiters with of the triangular membership functions of fuzzy sets Low 1 (L1), Low 2 (L2), Low 3 (L3), Medium 1 (M1), Medium 2 (M2), Medium 3 (M3), High 1 (H1), High 2 (H2) and High 3 (H3) for the output variables.

\begin{tabular}{ccc}
\hline Fuzzy sets & Type & Delimiters \\
\hline L1 & Triangular & {$[\mathrm{P}(0 \%)-1, \mathrm{P}(0 \%) \mathrm{P}(12.5 \%)]$} \\
L2 & Triangular & {$[\mathrm{P}(0 \%), \mathrm{P}(12.5 \%), \mathrm{P}(25 \%)]$} \\
L3 & Triangular & {$[\mathrm{P}(12.5 \%), \mathrm{P}(25 \%) \mathrm{P}(37.5 \%)]$} \\
M1 & Triangular & {$[\mathrm{P}(25 \%), \mathrm{P}(37.5 \%), \mathrm{P}(50 \%)]$} \\
M3 & Triangular & {$[\mathrm{P}(37.5 \%), \mathrm{P}(50 \%) \mathrm{P}(62.5 \%)]$} \\
H1 & Triangular & {$[\mathrm{P}(50 \%) \mathrm{P}(62.5 \%) \mathrm{P}(75 \%)]$} \\
H2 & Triangular & {$[\mathrm{P}(62.5 \%), \mathrm{P}(75 \%) \mathrm{P}(87.5 \%)]$} \\
H3 & Triangular & {$[\mathrm{P}(75 \%) \mathrm{P}(87.5 \%), \mathrm{P}(100 \%)]$} \\
& Triangular & {$[\mathrm{P}(87.5 \%), \mathrm{P}(100 \%), \mathrm{P}(100 \%)+1]$} \\
\hline
\end{tabular}

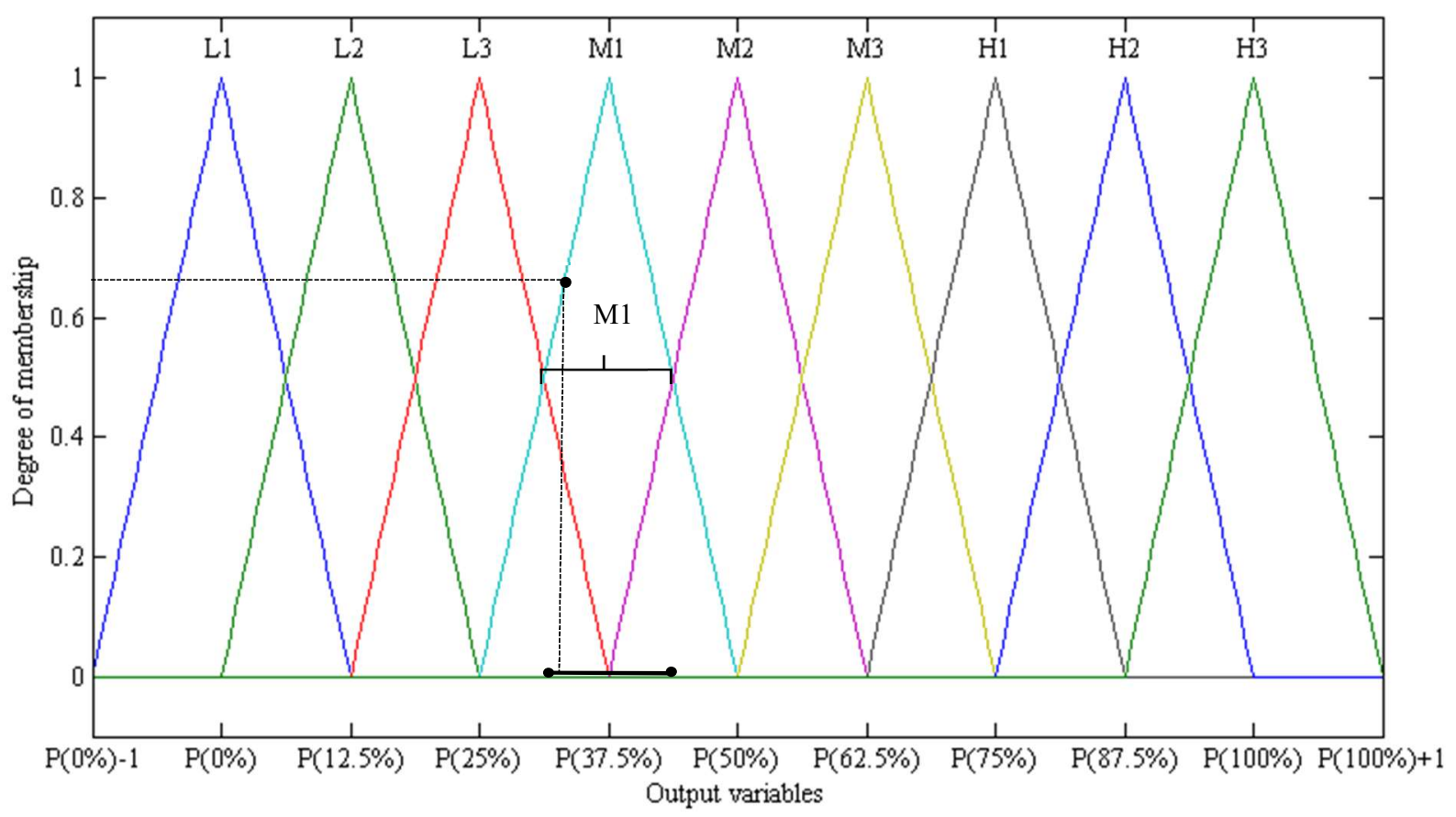

FIGURE 3. Pertinence functions of the output variables according to the used methodology proposed of percentiles and indication of the subinterval with higher degree of pertinence to the M1 fuzzy set. 


\section{Fuzzy Rules Base}

We considered the $9(3 \times 3)$ combinations among the fuzzy sets of the two input variables to obtain the rules base. Thus was created 9 pairs of the form Irrigation $\times$ Salinity according to methodology developed in Cremasco et al. (2010), Gabriel Filho et al. (2011), Putti (2015) and Gabriel Filho et al. (2016). Table 3 shows the points of each variable considered and the combinations of the fuzzy sets described.

TABLE 3. Combinations of input variables Irrigation and Salinity with the points of degree pertinence 1 associated with the fuzzy sets Low (L), Medium (M) and High (H) for the development of the fuzzy rules base.

\begin{tabular}{cccc}
\hline & Irrigation & & Salinity \\
\hline \multirow{2}{*}{ Fuzzy set } & $\begin{array}{c}\text { Point with degree of pertinence 1 } \\
\text { associated }\end{array}$ & $\begin{array}{c}\text { Point with degree of pertinence 1 } \\
\text { associated }\end{array}$ \\
\hline L & -60 & $\mathrm{~L}$ & 0.08 \\
L & -60 & $\mathrm{M}$ & 3 \\
L & -60 & $\mathrm{H}$ & 5 \\
M & -30 & $\mathrm{~L}$ & 0.08 \\
M & -30 & $\mathrm{M}$ & 3 \\
M & -30 & $\mathrm{H}$ & 5 \\
H & -10 & $\mathrm{~L}$ & 0.08 \\
H & -10 & $\mathrm{M}$ & 3 \\
H & -10 & $\mathrm{H}$ & 5 \\
\hline
\end{tabular}

The association of fuzzy sets combinations of the input variables with a fuzzy set of each output variable, which fully characterizes the rules base, was carried out by determining the greater degree of pertinence of the median value obtained from the 3 repetitions measured in experiment in each combination (Table 3 ).

It also highlights that the greatest degree of pertinence was adopted since, except for points with degree of pertinence 1, all other points of the interval $[P(0 \%), P(100 \%)]$ belong to two fuzzy sets of the output variables.

Thus, assuming that a combination shown in Table 3 may result as median value (from 3 measurements) that belongs to the fuzzy sets L3 and M1 of some output variable, and assuming that this value was located in the subinterval $\left[\frac{P(25 \%)+P(37.5 \%)}{2}, \frac{P(37.5 \%)+P(50 \%)}{2}[\right.$ showed in Figure 3, then such combination would be associated with the fuzzy set M1, since there is a greater degree of pertinence to this set.

In order to generalize the other associations, Table 4 shows the fuzzy sets related to their respective intervals. This relationship indicates that certain points of the range have greater degree of pertinence to the fuzzy set related. The intervals are related to domain partitions of each output variable.

TABLE 4. Intervals of points with greater pertinence degree associated with the fuzzy sets Low 1 (L1), Low 2 (L2), Low 3 (L3), Medium 1 (M1), Medium 2 (M2), Medium 3 (M3), High 1 (H1), High 2 (H2) and High 3 (H3) for the output variables.

\begin{tabular}{|c|c|}
\hline Output fuzzy set & Range with greater degree of pertinence \\
\hline L1 & $P(0 \%), \frac{P(0 \%)+P(12.5 \%)}{2}[$ \\
\hline L2 & {$\left[\frac{P(0 \%)+P(12.5 \%)}{2}, \frac{P(12.5 \%)+P(25 \%)}{2}[\right.$} \\
\hline L3 & {$\left[\frac{P(12.5 \%)+P(25 \%)}{2}, \frac{P(25 \%)+P(37.5 \%)}{2}\right]$} \\
\hline M1 & {$\left[\frac{P(25 \%)+P(37.5 \%)}{2}, \frac{P(37.5 \%)+P(50 \%)}{2}\right]$} \\
\hline M2 & $\frac{P(37.5 \%)+P(50 \%)}{2}, \frac{P(50 \%)+P(62.5 \%)}{2}$ \\
\hline M3 & $\frac{P(50 \%)+P(62.5 \%)}{2}, \frac{P(62.5 \%)+P(75 \%)}{2}$ \\
\hline H1 & {$\left[\frac{P(62,5 \%)+P(75 \%)}{2}, \frac{P(75 \%)+P(87,5 \%)}{2}\right]$} \\
\hline $\mathrm{H} 2$ & $\frac{P(75 \%)+P(87.5 \%)}{2}, \frac{P(87.5 \%)+P(100 \%)}{2}$ \\
\hline H3 & {$\left[\frac{P(87.5 \%)+P(100 \%)}{2}, P(100 \%)\right]$} \\
\hline
\end{tabular}


Alternative nomenclature is adopting for the output fuzzy sets (only as a generalization), denoting by $\mathrm{O} 1, \mathrm{O} 2$, O3, O4, O5, O6, O7, O8, O9 the fuzzy sets L1, L2, L3, M1, M2, M3, H1, H2, H3, respectively, we have that Table 4 can be represented by Table 5 .

TABLE 5. Generalization of the intervals of points with greater pertinence degree associated with the fuzzy sets $\mathrm{O} 1$, O2, O3, O4, O5, O6, O7, O8 and O9, representing respectively the fuzzy sets Low 1, Low 2, Low 3, Medium 1, Medium 2, Medium 3, High 1, High 2 and High 3 for the output variables.

\begin{tabular}{cc}
\hline Output variables & Associated fuzzy set \\
\hline O1 & {$\left[P(0), \frac{P(0)+P(k)}{2}\right]$} \\
Oi, $2 \leq i \leq 8$ & {$\left[\frac{P((i-2) k)+P((i-1) k)}{2}, \frac{P((i-1) k)+P(i k)}{2}[\right.$} \\
O9 & {$\left[\frac{P(7 k)+P(8 k)}{2}, P(8 k)\right]$}
\end{tabular}

It is noteworthy that the present method of using percentiles of experimental data was adopted in order to avoid subjectivity in the delimiters choice of the pertinence functions, creating also a generalization form of establishment of these functions for all variables. In addition, it is emphasized that the present system refers to the experiment information of this research, which does not prevent the use of the same methodology in other crops.

In addition, a rules base shown in the notation of Table 5 classify all output combinations associated with numbers from 1 to 9 , thus facilitating the visualization by the system users (researchers and farmers) of the rules generated by this method, featuring as an extractor method of rules base.

\section{Software used}

For the preparation of the FRBS were used an electronic spreadsheet and the Matlab ${ }^{\circledR}$ software, that the Faculty of Science and Engineering - FCE / UNESP, has the license to use. Also it was used the Toolbox Fuzzy Logic of software Matlab ${ }^{\circledR}$ determining the pertinence functions.

\section{RESULTS AND DISCUSSION}

With the determination of the measured data percentiles (Table 6) in the agronomic experiment conducted by Silva Junior (2012) and using the proposed methodology, the pertinence functions of the fuzzy sets of the output variables of this study were prepared (Figures 4 and 5).

TABLE 6. Percentiles $\mathrm{P}(12.5 \% . \mathrm{i}), \mathrm{i}=0,1, . .8$, of the output variables plant height $(\mathrm{PH}, \mathrm{cm})$, stem diameter $(\mathrm{SD}$, cm), leaf area $\left(\mathrm{LA}, \mathrm{cm}^{2}\right)$, green biomass $(\mathrm{GB}, \mathrm{g})$, dry biomass $(\mathrm{DB}, \mathrm{g})$, fruit number (FN, units), average fruit weight $(\mathrm{AFW}, \mathrm{g})$ and percentage of disabled fruits (PDF, \%).

\begin{tabular}{cccccccccc}
\hline Percentiles $(\%)$ & PH & SD & LA & GB & DB & FN & AFW & PDF \\
\hline $0.0 \%$ & 42.10 & 0.65 & 11.10 & 82.06 & 15.07 & 2.00 & 12.92 & 7.82 \\
$12.5 \%$ & 45.48 & 0.76 & 17.80 & 99.49 & 17.32 & 4.25 & 16.04 & 21.48 \\
$25.0 \%$ & 48.10 & 0.95 & 52.80 & 108.02 & 19.56 & 7.00 & 19.54 & 23.33 \\
$37.5 \%$ & 50.60 & 1.01 & 55.35 & 120.65 & 21.02 & 8.00 & 21.69 & 32.14 \\
$50.0 \%$ & 53.50 & 1.04 & 59.93 & 126.99 & 22.16 & 9.00 & 25.00 & 37.50 \\
$62.5 \%$ & 56.93 & 1.06 & 65.25 & 130.45 & 22.71 & 10.19 & 26.15 & 43.26 \\
$75.0 \%$ & 61.25 & 1.07 & 69.33 & 136.37 & 25.60 & 11.25 & 27.63 & 58.76 \\
$87.5 \%$ & 66.44 & 1.15 & 76.19 & 156.85 & 29.67 & 13.63 & 31.26 & 87.15 \\
$100.0 \%$ & 76.00 & 1.32 & 86.38 & 180.75 & 37.29 & 15.00 & 49.88 & 100.00 \\
\hline
\end{tabular}

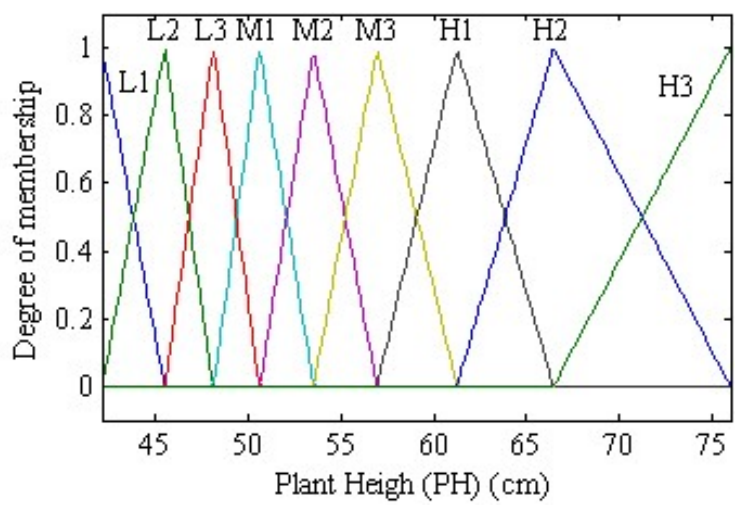

(a)

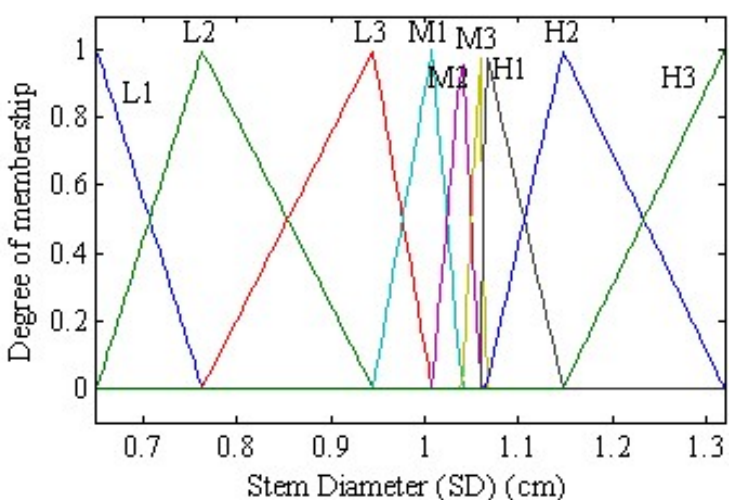

(b) 


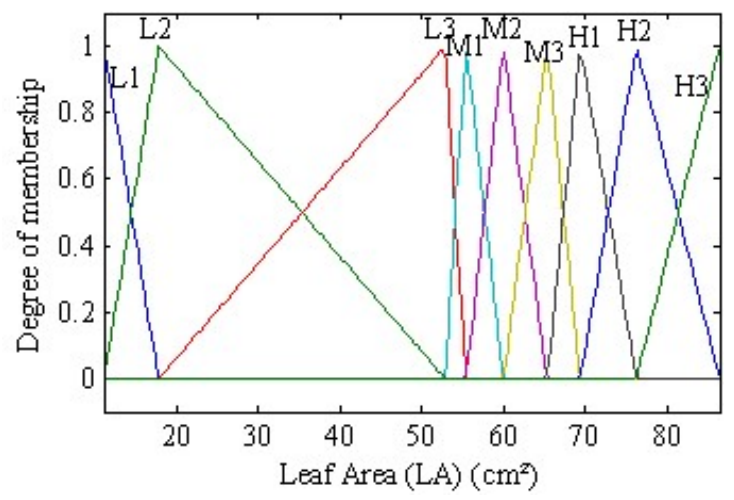

(c)

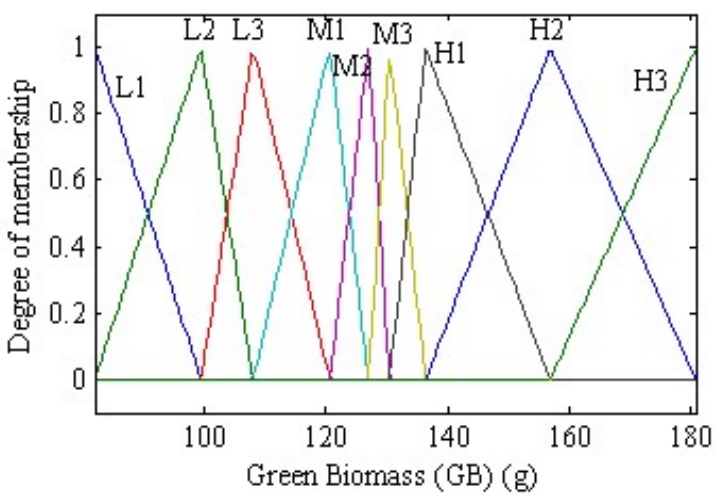

(d)

FIGURE 4. Triangular membership functions of fuzzy sets Low 1 (L1), Low 2 (L2), Low 3 (L3), Medium 1 (M1), Medium 2 (M2), Medium 3 (M3), High 1 (H1), High 2 (H2) and High 3 (H3) for the output variables (a) plant height (PH), (b) stem diameter (SD), (c) leaf area (LA) and (d) green biomass (GB).

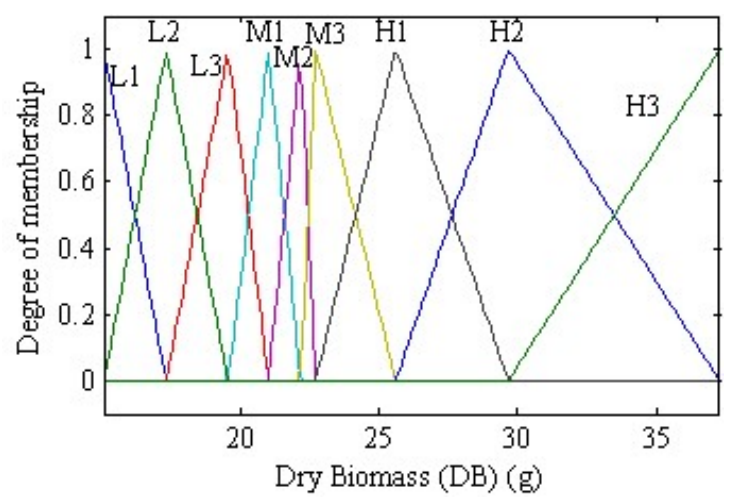

(a)

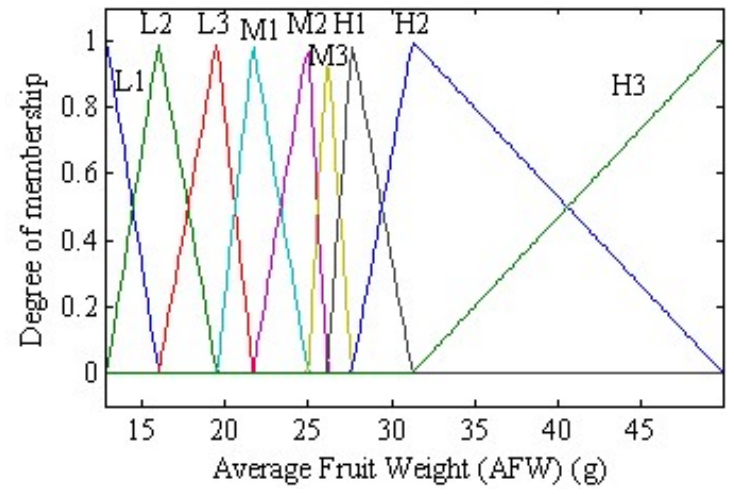

(c)

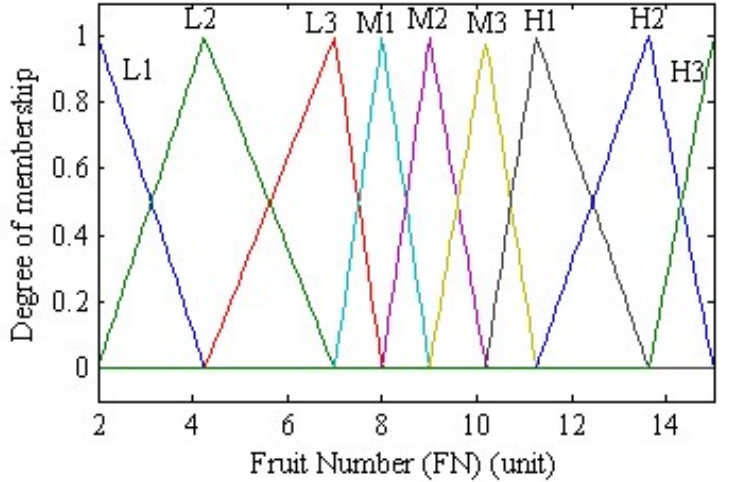

(b)

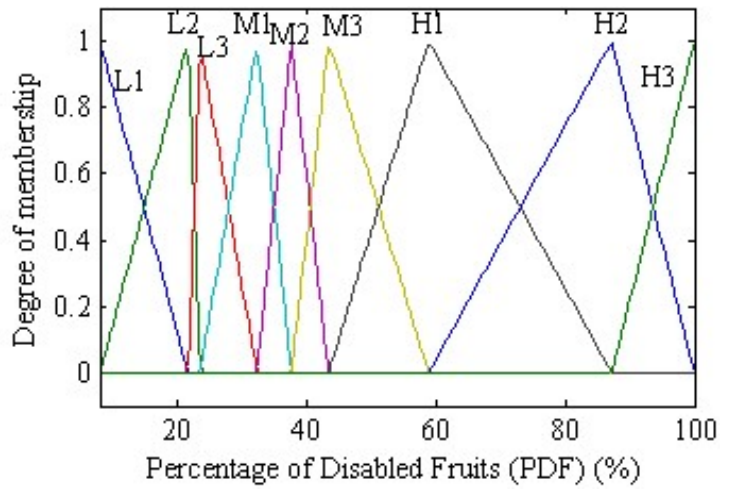

(d)

FIGURE 5. Triangular membership functions of fuzzy sets Low 1 (L1), Low 2 (L2), Low 3 (L3), Medium 1 (M1), Medium 2 (M2), Medium 3 (M3), High 1 (H1), High 2 (H2) and High 3 (H3) for the output variables (a) dry biomass (DB), (b) fruit number (FN), (c) average fruit weight (AFW) and (d) percentage of disabled fruit (PDF).

Figures 4 and 5 establish all partitions of the contradictions of the output variables, with the aid of the 9 fuzzy sets for each variable. Thus, any simulation of the fuzzy system will generate some result that will belong to some of these sets. It is important to note that, with the proposed methodology, it was possible to establish with precision all delimiters (Table 6) of the pertinence functions of these fuzzy sets. This enabled the creation of Table 7 intervals.

It is worth noting that many modeling works use a smaller amount of fuzzy sets in the output variables. This, of course, requires a limitation on the number of classes, partitions, and possibilities for the response (output) of rule bases, naturally decreasing the accuracy of the model. These characteristics (and with 5 fuzzy sets) can be found in the field of agrarian sciences in Luydmila et al. (2017) studying applications in agrometeorological models for productivity estimation, in Giusti \& Marsili-Libelli (2015) creating a support system for irrigation and water conservation in agriculture, in Mamann et al. (2018) in simulation of wheat production by nitrogen and hydrogel, and in Lima et al. (2010) to control soil matrix potential.

Moreover, keeping the nomenclature of output fuzzy sets similar to the input (Low, Medium and High), adding the numerals 1, 2 and 3, favors the understanding of the rule base.

More specifically, according to Tables 4 and 6 , it was possible to determine the intervals indicating the greatest degree of pertinence of each item of the output variables of a given fuzzy set (Table 7). 
TABLE 7. Intervals of points with greater pertinence degree associated with the fuzzy sets Low 1 (L1), Low 2 (L2), Low 3 (L3), Medium 1 (M1), Medium 2 (M2), Medium 3 (M3), High 1 (H1), High 2 (H2) and High 3 (H3) of the output variables plant height (PH), stem diameter (SD), leaf area (LA), green biomass (GB), dry biomass (DB), fruit number (FN), average fruit weight $(\mathrm{AFW})$ and percentage of disabled fruits (PDF).

\begin{tabular}{ccccccccc}
\hline \multirow{2}{*}{$\begin{array}{c}\text { Set fuzzy } \\
\text { output }\end{array}$} & PH & SD & LA & GB & DB & FN & AFW & PDF \\
\hline L1 & {$[42.1 ; 43.8]$} & {$[0.65 ; 0.71]$} & {$[11.1 ; 14.5]$} & {$[82.1 ; 90.8]$} & {$[15.1 ; 16.2]$} & {$[2 ; 3.1]$} & {$[12.9 ; 14.5]$} & {$[7.8 ; 14.7]$} \\
L2 & {$[43.8 ; 46.8]$} & {$[0.71 ; 0.86]$} & {$[14.5 ; 35.3]$} & {$[90.8 ; 103.8]$} & {$[16.2 ; 18.4]$} & {$[3.1 ; 5.6]$} & {$[14.5 ; 17.8]$} & {$[14.7 ; 22.4]$} \\
L3 & {$[46.8 ; 49.4]$} & {$[0.86 ; 0.98]$} & {$[35.3 ; 54.1]$} & {$[103.8 ; 114.3]$} & {$[18.4 ; 20.3]$} & {$[5.6 ; 7.5]$} & {$[17.8 ; 20.6]$} & {$[22.4 ; 27.7]$} \\
M1 & {$[49.4 ; 52.1]$} & {$[0.98 ; 1.03]$} & {$[54.1 ; 57.6]$} & {$[114.3 ; 123.8]$} & {$[20.3 ; 21.6]$} & {$[7.5 ; 8.5]$} & {$[20.6 ; 23.3]$} & {$[27.7 ; 34.8]$} \\
M2 & {$[52.1 ; 55.2]$} & {$[1.03 ; 1.05]$} & {$[57.6 ; 62.6]$} & {$[123.8 ; 128.7]$} & {$[21.6 ; 22.4]$} & {$[8.5 ; 9.6]$} & {$[23.3 ; 25.6]$} & {$[34.8 ; 40.4]$} \\
M3 & {$[55.2 ; 59.1]$} & {$[1.05 ; 1.07]$} & {$[62.6 ; 67.3]$} & {$[128.7 ; 133.4]$} & {$[22.4 ; 24.2]$} & {$[9.6 ; 10.7]$} & {$[25.6 ; 26.9]$} & {$[40.4 ; 51]$} \\
H1 & {$[59.1 ; 63.8]$} & {$[1.07 ; 1.11]$} & {$[67.3 ; 72.8]$} & {$[133.4 ; 146.6]$} & {$[24.2 ; 27.6]$} & {$[10.7 ; 12.4]$} & {$[26.9 ; 29.4]$} & {$[51 ; 73]$} \\
H2 & {$[63.8 ; 71.2]$} & {$[1.11 ; 1.24]$} & {$[72.8 ; 81.3]$} & {$[146.6 ; 168.8]$} & {$[27.6 ; 33.5]$} & {$[12.4 ; 14.3]$} & {$[29.4 ; 40.6]$} & {$[73 ; 93.6]$} \\
H3 & {$[71.2 ; 76]$} & {$[1.24 ; 1.32]$} & {$[81.3 ; 86.4]$} & {$[168.8 ; 180.8]$} & {$[33.5 ; 37.3]$} & {$[14.3 ; 15]$} & {$[40.6 ; 49.9]$} & {$[93.6 ; 100]$} \\
\hline
\end{tabular}

According to the methodological proposal for drafting the rules base, it was possible to generate the rules used by the fuzzy system in question to classify the output variables according to the chosen treatment (Table 8).

It is noting that the process of the present paper is not supervised by specialists (unsupervised system). Nevertheless, generated fuzzy models taken from interviews witch specialists are extremely useful for advancing the understanding of phenomena in the agrarian sciences, such as models for estimate the effects of global warming on the vitality of orchids (Putti et al., 2017), determination of the agricultural optimal cropping pattern (Neamatollahi et al., 2017), elicitation of expert knowledge for evaluation of agricultural production systems (Cornelissen et al., 2003), scheduling tillage operations (Thangavadivelu \& Colvin, 1997) and evaluation of uncertainty in cassava chain (Gabriel Filho et al., 2015).

However, for models that must be generated from experimentally measured data, it is appropriate to propose a modeling method that will fit directly to the data, such that as proposed in the present work, generating a rule base such as Table 8.

Models of this type, in which the system based on fuzzy rules have their rules generated with computational, mathematical and/or statistical methods are called unsupervised models and can be observed in the works of Yang et al. (2003) in development of a herbicide application map, Cremasco et al. (2010) in applications for the energy evaluation of poultry industry companies, Gabriel Filho et al. (2011) in evaluation of livestock slaughtering, Murmu \& Biswas (2015) in crop classification, Daneshmand et al. (2015) modeling minimum temperature for analysis of climate indices and Viais Neto et al. (2018) in evaluation of cherry tomato seedlings production.

Furthermore, the form of rule generation (rules of the if / then type) makes it possible to use the system's own rules in the form of a practical result for farmers.

TABLE 8. Fuzzy rules relating all combinations between the fuzzy sets Low (L), Medium (M) and High (H) of input variables Irrigation and Salinity, and the fuzzy sets Low 1 (L1), Low 2 (L2), Low 3 (L3), Medium 1 (M1), Medium 2 (M2), Medium 3 (M3), High 1 (H1), High 2 (H2) and High $3(\mathrm{H} 3)$ of output variables plant height (PH), stem diameter (SD), leaf area (LA), green biomass (GB), dry biomass (DB), fruit number (FN), average fruit weight (AFW) and percentage of disabled fruits (PDF).

\begin{tabular}{|c|c|c|c|c|c|c|c|c|c|}
\hline \multicolumn{2}{|c|}{ Input variables } & \multicolumn{8}{|c|}{ Output variables } \\
\hline Irrigation & Salinity & $\mathrm{PH}$ & SD & LA & GB & DB & $\mathrm{FN}$ & AFW & PDF \\
\hline $\mathrm{L}$ & $\mathrm{L}$ & M1 & M2 & M3 & M2 & M3 & $\mathrm{L} 1$ & M2 & $\mathrm{H} 3$ \\
\hline $\mathrm{L}$ & M & M1 & M2 & M3 & M2 & M1 & M2 & M3 & L3 \\
\hline $\mathrm{L}$ & $\mathrm{H}$ & M2 & H1 & M2 & L2 & L3 & L2 & L3 & M1 \\
\hline M & $\mathrm{L}$ & L3 & M3 & $\mathrm{H} 2$ & $\mathrm{H} 1$ & H1 & M1 & H1 & $\mathrm{H} 2$ \\
\hline M & $\mathrm{M}$ & M3 & M3 & H1 & M3 & M2 & M3 & L2 & M3 \\
\hline M & $\mathrm{H}$ & L3 & M2 & M1 & M1 & L3 & M1 & L2 & M3 \\
\hline $\mathrm{H}$ & $\mathrm{L}$ & $\mathrm{H} 2$ & $\mathrm{H} 2$ & $\mathrm{H} 2$ & $\mathrm{H} 2$ & $\mathrm{H} 2$ & $\mathrm{H} 2$ & $\mathrm{H} 3$ & L1 \\
\hline $\mathrm{H}$ & M & $\mathrm{H} 3$ & L2 & L2 & $\mathrm{H} 1$ & $\mathrm{H} 2$ & $\mathrm{H} 2$ & H1 & L2 \\
\hline $\mathrm{H}$ & $\mathrm{H}$ & H1 & L1 & L1 & L1 & L2 & $\mathrm{H} 2$ & M1 & M1 \\
\hline
\end{tabular}

The first line of Table 8 is explained as follows: "If (irrigation is L and salinity is L), then (plant height is M1; diameter stem is M2, leaf area is M3; green biomass is M2, dry biomass is M3; fruit number is L1; average fruit weight is M2 and percentage of disabled fruit is H3)". The other lines are interpreted analogously. 
Using the nomenclature presented in Table 5, it was possible determine Table 9 that is an alternative generalization of Table 8 for the classification of the output variables in relation to the chosen treatment.

TABLE 9. Fuzzy rules relating all combinations between the fuzzy sets Low (L), Medium (M) and High (H) of input variables Irrigation and Salinity, and the fuzzy sets the fuzzy sets O1, O2, O3, O4, O5, O6, O7, O8 and O9, representing respectively the fuzzy sets Low 1 (L1), Low 2 (L2), Low 3 (L3), Medium 1 (M1), Medium 2 (M2), Medium 3 (M3), High 1 (H1), High 2 (H2) and High $3(\mathrm{H} 3)$ for the output variables plant height $(\mathrm{PH})$, stem diameter (SD), leaf area (LA), green biomass (GB), dry biomass (DB), fruit number (FN), average fruit weight (AFW) and percentage of disabled fruits (PDF).

\begin{tabular}{|c|c|c|c|c|c|c|c|c|c|}
\hline \multicolumn{2}{|c|}{ Input variables } & \multicolumn{8}{|c|}{ Output variables } \\
\hline Irrigation & Salinity & $\mathrm{PH}$ & SD & LA & GB & DB & $\mathrm{FN}$ & AFW & PDF \\
\hline $\mathrm{L}$ & $\mathrm{L}$ & $\mathrm{O} 4$ & O5 & O6 & O5 & O6 & $\mathrm{O} 1$ & O5 & O9 \\
\hline $\mathrm{L}$ & M & $\mathrm{O} 4$ & O5 & O6 & $\mathrm{O} 5$ & $\mathrm{O} 4$ & O5 & O6 & $\mathrm{O} 3$ \\
\hline $\mathrm{L}$ & $\mathrm{H}$ & O5 & O7 & O5 & $\mathrm{O} 2$ & $\mathrm{O} 3$ & $\mathrm{O} 2$ & $\mathrm{O} 3$ & $\mathrm{O} 4$ \\
\hline M & $\mathrm{L}$ & $\mathrm{O} 3$ & O6 & O8 & $\mathrm{O} 7$ & O7 & $\mathrm{O} 4$ & O7 & O8 \\
\hline M & M & O6 & O6 & $\mathrm{O} 7$ & O6 & O5 & O6 & $\mathrm{O} 2$ & O6 \\
\hline M & $\mathrm{H}$ & $\mathrm{O} 3$ & O5 & $\mathrm{O} 4$ & $\mathrm{O} 4$ & $\mathrm{O} 3$ & $\mathrm{O} 4$ & $\mathrm{O} 2$ & O6 \\
\hline $\mathrm{H}$ & $\mathrm{L}$ & $\mathrm{O} 8$ & O8 & $\mathrm{O} 8$ & O8 & O8 & O8 & O9 & O1 \\
\hline $\mathrm{H}$ & M & O9 & $\mathrm{O} 2$ & $\mathrm{O} 2$ & $\mathrm{O} 7$ & O8 & O8 & O7 & $\mathrm{O} 2$ \\
\hline $\mathrm{H}$ & $\mathrm{H}$ & $\mathrm{O} 7$ & $\mathrm{O} 1$ & $\mathrm{O} 1$ & $\mathrm{O} 1$ & $\mathrm{O} 2$ & O8 & $\mathrm{O} 4$ & $\mathrm{O} 4$ \\
\hline
\end{tabular}

Is noteworthy that for the determination of the fuzzy system rules (Tables 8 and 9), in which are related the fuzzy sets of the input with the output variables; calculating the median values for each combination of input fuzzy sets. Additionally, the classifications presented in these tables are possibly invariant or have no significant changes if an experiment was carried out under the same conditions during the same period described which makes the result relevant.

For plant height output variable, we have the following values (Table 10) measured for some combinations of input fuzzy sets (for other output variables and other combinations of input fuzzy sets, the procedure performed was analogous).

TABLE 10. Procedure performed to the elaboration the fuzzy rules for some combinations of the input fuzzy sets Low Irrigation and Low, Medium and High Salinity of plant height output variable.

\begin{tabular}{cc|cc}
\hline \multicolumn{2}{c|}{ Input fuzzy set } & $\begin{array}{c}\text { Average values of } 3 \text { repetitions of } \\
\text { plant height variable }\end{array}$ & $\begin{array}{c}\text { Associated fuzzy set (together with greater } \\
\text { degree of pertinence) }\end{array}$ \\
\cline { 1 - 2 } Irrigation & Salinity & 50.0 & $\mathrm{M} 1$ \\
$\mathrm{~L}(-60 \mathrm{kPa})$ & $\mathrm{L}\left(0.08 \mathrm{dS} \mathrm{m}^{-1}\right)$ & 49.7 & $\mathrm{M} 1$ \\
$\mathrm{~L}(-60 \mathrm{kPa})$ & $\mathrm{M}\left(3 \mathrm{dS} \mathrm{m}^{-1}\right)$ & 53.5 & $\mathrm{M} 2$ \\
$\mathrm{~L}(-60 \mathrm{kPa})$ & $\mathrm{H}\left(5 \mathrm{dS} \mathrm{m}^{-1}\right)$ & & \\
\hline
\end{tabular}

Therefore, for the combination of the fuzzy sets L of the variable irrigation and L of the salinity variable, we have from Table 10 that the average value of 3 repetitions (by the database corresponds to the value $50 \mathrm{~cm}$ ) belongs to two fuzzy sets of plant height variable, namely, L3 and M1. This situation can be seen in Figures 4 (a) and 6. As this value has greater degree of pertinence to the fuzzy set M1, the rule is created: "If irrigation is L and salinity is L, then height is MI".

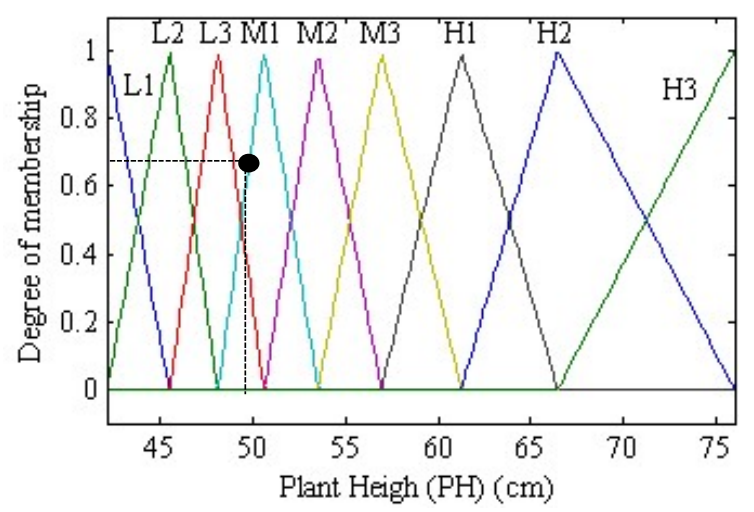

FIGURE 6. Method of association applicated in input fuzzy set Low Irrigation and Low Salinity of plant height output variable, resulting in an output fuzzy set Medium 1. 


\section{CONCLUSIONS}

The fuzzy modeling developed will analyze intermediate regions to trial levels and weave other conclusions about the tomato growth and productivity.

For the preparation of this fuzzy model, it should be noted that it has not used the expert opinion for the development of rules base, and that the established methodology allows developing it from the response data sets of the trial.

Finally, in agreement with the theoretical results presented, the developed mathematical model can be used for other crops on which it has collected data in a trial, since the appropriate methodological adjustments are made such as experimental factors, input variables, output variables and numbers of input fuzzy set.

\section{ACKNOWLEDGEMENTS}

The Authors are grateful for the Postgraduate in Agronomy/Irrigation and drainage (of School of Agriculture, São Paulo State University-UNESP) and the Postgraduate Program in Agribusiness and Development (of School of Sciences and Engineering, São Paulo State University UNESP) for the scientific contribution made available.

This work was supported by the National Council for Scientific and Technological Development (CNPq) (grant number 313570/2017-5) for the research productivity grant granted to the last author.

\section{REFERENCES}

Alvarenga MAR (2004) Production systems in the open and protected environment. In: Alvarenga MAR (ed). Tomato: Field, greenhouse and hydroponic production. Lavras, UFLA.

Bergougnoux V (2014) The history of tomato: From domestication to biopharming. Biotechnology Advances 32(1):170-189. DOI: https://doi.org/10.1016/j.biotechadv.2013.11.003

Cornelissen AMG, Van Den Berg J, Koops WJ, Kaymak U (2003) Elicitation of expert knowledge for fuzzy evaluation of agricultural production systems. Agriculture, Ecosystems \& Environment 95(1):1-18. DOI:

https://doi.org/10.1016/S0167-8809(02)00174-3.

Cremasco CP, Gabriel Filho LRA, Cataneo A (2010) Methodology for determination of fuzzy controller pertinence functions for the energy evaluation of poultry industry companies. Energia na Agricultura 25:21-39. DOI: http://dx.doi.org/10.17224/EnergAgric.2010v25n1p21-39

Daneshmand H, Tavousi T, Khosravi M, Tavakoli S (2015) Modeling minimum temperature using adaptive neuro-fuzzy inference system based on spectral analysis of climate indices: A case study in Iran. Journal of the Saudi Society of Agricultural Sciences 14(1):33-40. DOI: https://doi.org/10.1016/j.jssas.2013.06.001.

Filgueira FAR (2013) New manual of olericultura: Modern agro-technology in the production and commercialization of vegetables. Viçosa, UFV, 421p.
Gabriel Filho LRA, Cremasco CP, Putti FF, Chacur MGM (2011) Application of fuzzy logic for the evaluation of livestock slaughtering. Engenharia Agrícola 31(4):813825. DOI: http://dx.doi.org/10.1590/S010069162011000400019

Gabriel Filho LRA, Putti FF, Cremasco CP, Bordin D, Chacur MGM, Gabriel LRA (2016) Software to assess beef cattle body mass through the fuzzy body mass index. Engenharia Agrícola 36(1):179-193. DOI: http://dx.doi.org/10.1590/1809-4430-

Eng.Agric.v36n1p179-193/2016

Gabriel Filho LRA, Pigatto GAS, Lourenzani AEBS (2015) Fuzzy rule-based system for evaluation of uncertainty in cassava chain. Engenharia Agrícola 35(2):350-367. DOI: http://dx.doi.org/10.1590/1809-4430Eng.Agric.v35n2p350-367/2015

Giusti E, Marsili-Libelli S (2015) A fuzzy decision support system for irrigation and water conservation in agriculture. Environmental Modelling \& Software 63:73-86. DOI: https://doi.org/10.1016/j.envsoft.2014.09.020

Lima FMC, Silva AS, Filgueira HJA, Gomes HP (2010) Control of soil matrix potential by fuzzy logic. Irriga 15(4):431-442.

Luydmila S, Mikhail S, Imran A, Tamara A, Anatoliy C (2017) Application of fuzzy set theory in agrometeorological models for yield estimation based on statistics. Procedia Computer Science 120:820-829. DOI: https://doi.org/10.1016/j.procs.2017.11.313

Mamann ATW, Brezolin AP, Scremin AH, Reginatto DC, Matos ES, Shirahige FH, Melo PCT (2012) Performance of tomato hybrids of indeterminate growth as a function of plant management systems. Horticultura Brasileira 30(2):240-245. DOI: http://dx.doi.org/10.1590/S010205362012000200010

Matos, ES; Shirahige, FH; Melo, PCT (2012) Performance of tomato hybrids of indeterminate growth as a function of plant management systems. Horticultura Brasileira 30(2):240-245. DOI: http://dx.doi.org/10.1590/S010205362012000200010

Mishra B, Nishad AK, Singh SR (2014) Fuzzy Multifractional Programming for Land Use Planning in Agricultural Production System, Fuzzy Information and Engineering 6(2):245-262. DOI: https://doi.org/10.1016/j.fiae.2014.08.008

Murmu S, Biswas S (2015) Application of fuzzy logic and neural network in crop classification: a review. Aquatic Procedia (4):1203-1210. DOI: https://doi.org/10.1016/j.aqpro.2015.02.153

Neamatollahi E, Vafabakhshi J, Jahansuz MR, Sharifzadeh F (2017) Agricultural optimal cropping pattern determination based on fuzzy system. Fuzzy Information and Engineering 9(4):479-491. DOI: https://doi.org/10.1016/j.fiae.2017.12.004 
Oliveira BC, Cardoso MAA, Oliveira JC, Oliveira FA, Cavalcante LF (2007) Productive characteristics of tomatoes submitted to different levels of salts in irrigation water. Revista Brasileira de Engenharia Agrícola e Ambiental 11(1):11-16. DOI: http://dx.doi.org/10.1590/S1415-43662007000100002

Pereira DF, Bighi CA, Gabriel Filho LRA, Cremasco CPC (2008) Sistema fuzzy para estimativa do bem-estar de matrizes pesadas. Engenharia Agrícola 28(4):624-633. DOI: http://dx.doi.org/10.1590/S010069162008000400002

Putti FF (2015) Analysis of biometric and nutritional indicators of lettuce (Lactuca sativa L.) culture irrigated with magnetically treated water using fuzzy modeling. $\mathrm{PhD}$ Thesis, São Paulo State University (UNESP), School of Agriculture.

Putti FF, Gabriel Filho LRA, Cremasco CP, Bonini Neto A, Bonini CSB, Reis AR (2017) A Fuzzy mathematical model to estimate the effects of global warming on the vitality of Laelia purpurata orchids. Mathematical Biosciences 288:124-129. DOI:

https://doi.org/10.1016/j.mbs.2017.03.005

Putti FF, Gabriel Filho LRA, Silva AO, Ludwig R, Gabriel CPC (2014) Fuzzy logic to evaluate vitality of catasetum fimbiratum species (Orchidacea). Revista Irriga 19(3):405413. DOI:

http://dx.doi.org/10.15809/irriga.2014v19n3p405

Putti FF, Kummer ACB, Grassi Filho H, Gabriel Filho LRA, Cremasco CP (2017) Fuzzy modeling on wheat productivity under different doses of sludge and sewage effluent. Engenharia Agrícola, 37(6):1103-1115. DOI: http://dx.doi.org/10.1590/1809-4430-

eng.agric.v37n6p1103-1115/2017

Rodríguez E, Peche R, Garbisu C, Gorostiza I, Epelde L, Artetxe U, Irizar A, Soto M, Becerril JM, Etxebarria J (2016) Dynamic Quality Index for agricultural soils based on fuzzy logic. Ecological Indicators 60:678-692. DOI: http://dx.doi.org/10.1016/j.ecolind.2015.08.016.
Rosa CLS, Soares AG, Freitas DFGC, Rocha MC, Ferreira JC, Godoy RLO (2011) Physico-chemical, nutritional and instrumental characterization of four accessions of Italian tomato (Lycopersicum esculentum Mill) of the 'Heirloom' type produced under organic management for the elaboration of concentrated pulp. Alimentos e Nutrição 22(4):649-656. DOI:

http://serv-bib.fcfar.unesp.br/seer/index.php/alimentos/arti cle/view/1640

Santana MJ, Vieira TA, Barreto AC (2009) Effect of soil water replenishment levels on tomato productivity. Horticultura Brasileira 27(2):1378-1384.

Santos FFB, Ribeiro A, Siqueira WJ, Melo AMT (2011) Agronomic performance of table tomato F1 hybrids. Horticultura Brasileira 29(3):304-310. DOI: http://dx.doi.org/10.1590/S0102-05362011000300008

Silva Junior JF (2012) Growth of tomato in different levels of irrigation and salinity. MSc Dissertation, São Paulo State University (UNESP), School of Agriculture.

Thangavadivelu S, Colvin TS (1997) Fuzzy-logic-based decision support system for scheduling tillage operations. Engineering Applications of Artificial Intelligence 10(5):463-472. DOI: https://doi.org/10.1016/S09521976(97)00023-7.

Viais Neto DS, Pradela VA, Gabriel Filho LRA, Cremasco CP, Maria ACG, Oliveira GSD (2018) Fuzzy modeling for evaluation of cherry tomato seedlings production using different doses of polymers and irrigation levels. Colloquium Agrariae. 14(3):93-103. DOI: http://dx.doi.org/10.5747/ca.2018.v14.n3.a231.

Yang C-C, Prasher SO, Landry J-A, Ramaswamy HS (2003) Development of a herbicide application map using artificial neural networks and fuzzy logic. Agricultural Systems 76(2):561-574. DOI: https://doi.org/10.1016/S0308-521X(01)00106-8.

Zadeh LA (1965) Fuzzy sets. Information and Control 8:338-353 DOI: https://doi.org/10.1016/S00199958(65)90241-X 